\title{
Oviposition Activity and Seasonal Pattern of a Population of Aedes (Stegomyia) aegypti (L.) (Diptera: Culicidae) in Subtropical Argentina
}

\author{
María Victoria Micieli/ ${ }^{+}$, Raúl Ernesto Campos*
}

Centro de Estudios Parasitológicos y de Vectores, Universidad Nacional de La Plata, Calle 2 no. 584, (1900) La Plata, Buenos

Aires, Argentina *Instituto de Limnología “Dr. Raúl A. Ringuelet”, La Plata, Buenos Aires, Argentina

Monthly oviposition activity and the seasonal density pattern of Aedes aegypti were studied using larvitraps and ovitraps during a research carried out by the Public Health Ministry of Salta Province, in Tartagal, Aguaray and Salvador Mazza cities, in subtropical Argentina. The A. aegypti population was active in both dry and wet seasons with a peak in March, accordant with the heaviest rainfall. From May to November, the immature population level remained low, but increased in December. Ae. aegypti oviposition activity increased during the fall and summer, when the relative humidity was $60 \%$ or higher. Eggs were found in large numbers of ovitraps during all seasons but few eggs were observed in each one during winter. The occurrence and the number of eggs laid were variable when both seasons and cities were compared. The reduction of the population during the winter months was related to the low in the relative humidity of the atmosphere. Significant differences were detected between oviposition occurrences in Tartagal and Aguaray and Salvador Mazza cities, but no differences in the number of eggs were observed. Two factors characterize the seasonal distribution pattern of Ae. aegypti in subtropical Argentina, the absence of a break during winter and an oviposition activity concomitant of the high relative humidity of the atmosphere.

Key words: Aedes aegypti - oviposition - seasonal variation - subtropical Argentina

Dengue is a human mosquito-borne disease present in Argentina since the first outbreak occurred in 1916 (Gaudino 1916). The dengue epidemic of 1998 affected 19 people in Tartagal, in the Salta Province of Northwestern Argentina (Avilés et al. 1999). Others cases of infected people were recorded during 2002, by the National Public Health Ministry, in the Buenos Aires Province. These infections were attributed to foreign transmission.

Carbajo et al. (2001) speculate that the entrance of the dengue virus into Argentina may be a consequence of travelers bringing the infection from neighboring countries. Unfortunately no study has corroborated this hypothesis nor that of the possibility of an endemic transmission within the country. On the basis of the main road and airport map these authors suppose that the virus was introduced through the Center and North of the country. In addition, they suggest that the roads connecting Argentina with north infected countries would be the main access, favored by the climatic conditions.

Though natural infection of mosquitoes with dengue viruses has not been reported in Argentina, Aedes (Stg.) aegypti (L.) is suspected to be locally responsible for the transmission because no other potential vector was reported at the time of the epidemic in Salta Province.

This paper is the scientific contribution no. 733 of the Instituto de Limnología "Dr. R. A. Ringuelet".

${ }^{+}$Corresponding author. Fax: +54-221-4232327. E-mail: vmicieli@museo.fcnym.unlp.edu.ar

Received 23 July 2002

Accepted 30 June 2003
Studies made before the Ae. aegypti's eradication in 1963 from Argentina date from 1950's and 1960's (Ousset et al. 1967). Since the recent infestation in 1986 (OPS 1990), the studies on the Ae. aegypti population were carried out in dwellings and cemeteries in the main cities of the temperate region $\left(29^{\circ} \mathrm{S}\right.$. lat. $-35^{\circ} \mathrm{S}$. lat.). The recent study of Vezzani et al. (2001) reported temporal changes and changes in the development time, survival and sex ratio of Ae. aegypti in Buenos Aires City (East) and Domínguez et al. (2000), in Córdoba Province (Center). Avilés et al. (1997) established the present distribution and Almirón et al. (1999) studied the preference of the oviposition site of Ae. aegypti in Córdoba. Recent dengue transmission risk maps of Argentina were delineated by Carbajo et al. (2001) on a theoretical basis and on historical data. These authors predict maximum risk of this disease in subtropical Northern and Northeastern regions of the country throughout the year, and in temperate region during summer.

To get know the present situation of the Ae. aegypti population and the consequences of the epidemic occurred in 1998, the Public Health Ministry of Salta Province (PHMS) initiated permanent monitoring of immature $\mathrm{Ae}$. aegypti in Tartagal and the neighboring areas of the Northwestern frontier with Bolivia. This report is a summary of results of weekly oviposition activity, and seasonal pattern of immature Ae. aegypti in domestic populations, monitored in three localities of Salta Province, Argentina.

\section{MATERIALS AND METHODS}

Study site - Field studies were conducted from February 2000 through February 2001 in the cities of Tartagal (450m a.s.1.), Aguaray (565m a.s.1.) and Salvador Mazza 
(590 m a.s.1.), located in Salta Province ( $22^{\circ}$ S. lat. $-26^{\circ} 30^{\prime}$ S. lat.), at Northwestern Argentina in a subtropical region. The cities lie in that order, from North to South, along the route that leads to Bolivia. The human population is of 7500 in Aguaray, 17000 in Salvador Mazza and 68000 in Tartagal. During the study period the annual rainfall was $1049 \mathrm{~mm}$. The mean daily temperature ranged from $13.9^{\circ} \mathrm{C}$ in July to $27.3^{\circ} \mathrm{C}$ in January and average relative humidity ranged from $45 \%$ in September to $83 \%$ in March. These data were recorded at the meteorological station in Tartagal.

Samples - Immature stage of Ae. aegypti were sampled weekly, with larvitraps made of discarded tires cut in half used by the Public Health Ministry in their monitoring routine. Within the urban areas of Tartagal, Aguaray and Salvador Mazza 55, 15, and 30 points were chosen, respectively, for monitoring. Larvitraps were placed outdoors in the shadow of the private houses, at $\pm 1 \mathrm{~m}$ above the ground. This distribution was established and the sites chosen by the PHMS. The entire liquid content of each tire was removed weekly, and fourth instar larvae and pupae were counted and identified according to Christopher (1960). After the sampling, water was returned to the original tire. A sample from each tire was fixed with alcohol $70 \%$ and forwarded to the laboratory for species identification.

Ovipositions of Ae. aegypti were monitored using wood paddles with thick brown paper $(8 \times 6 \mathrm{~cm})$, attached to the internal wall at the water level of the larvitrap. After seven days exposure, each paddle was removed and replaced by a new egg-free paddle. Upon removal, each paddle was dried, packed in a plastic bag and mailed to the Centro de Estudios Parasitológicos y de Vectores (Cepave). On arrival at the laboratory, the Aedes' eggs were counted and submerged in tap water. A proportion of the hatched larvae was reared to adulthood for identification. No other species but Ae. aegypti were recorded.

Oviposition activity was expressed as the occurrence of eggs (number of positive ovitrap/week), and the quantity of eggs laid (eggs number)/ovitrap/week. To express the relative monthly abundance of immature Ae. aegypti stages, Williams'mean (Haddow 1960) was used because zero values occurred. This average was plotted as a percent of the total samples.

The study area in Salvador Mazza was treated with insecticide (Abate ${ }^{\circledR}$, brand label makes no recommendations regarding its use) from January to October 2000, and in January and February 2001; and those in Aguaray and Tartagal from January to April and in December 2000, and from January to March 2001.

Statistical analysis - Ae. aegypti seasonal abundance was correlated with rainfall, temperature and relative humidity by the use of Pearson's coefficient. The mean number of eggs, larvae and pupae of Ae. aegypti and the occurrence of oviposition were compared between localities with the Kruskal-Wallis test, and post hoc with the Student-Newman-Keuls probability test. The coefficient of variation $(\mathrm{Cv})$ was estimated for the occurrence of oviposition and egg quantities laid per locality and comparisons between the two variables were made using the Wilcoxon Pair test.

\section{RESULTS}

Monthly fluctuations of immature Ae. aegypti population - Immature Ae. aegypti were recorded in $85 \%$ $\left(\mathrm{n}_{\text {weeks sampled }}=54\right)$ of the weeks sampled in Salvador Mazza, $98 \%\left(\mathrm{n}_{\text {w.s. }}=52\right)$ in Aguaray and in $96.3 \%\left(\mathrm{n}_{\text {w.s. }}=\right.$ 54) in Tartagal. Associated Culex and Toxorhynchites mosquitoes were caught in the larvitraps, but were not taken into account in this study.

It was in March 2000 at all three sites that the maximum abundance of Ae. aegypti larvae and pupae (Fig. 1) was observed representing 53\% (Aguaray), 22\% (Tartagal) and $15 \%$ (Salvador Mazza) of the total of individuals collected during this year. A second peak occurred in Salvador Mazza in February 2001 (21\%). Ae. aegypti larvae and pupae were scarce in June and July when the mean temperatures were $16^{\circ}$ and $14^{\circ} \mathrm{C}$, respectively (Fig. 2).

The Ae. aegypti seasonal pattern responded fairly closely to variations in rainfall. The population peak in March corresponded to the heaviest rainfall (Figs 1, 2B), however, the only significant correlation occurred in Aguaray $(\mathrm{r}=0.59, \mathrm{P}<0.05)$. In Tartagal, the major correlation $(\mathrm{r}=0.56, \mathrm{P}<0.05)$ was that with relative humidity.

The lowest abundance of Ae. aegypti occurred from May through November. The population of Ae. aegypti increased in December in all three localities (Fig. 1), after rainfall had occurred in November (Fig. 2B). During this month, the relative humidity was above $70 \%$, and the mini-
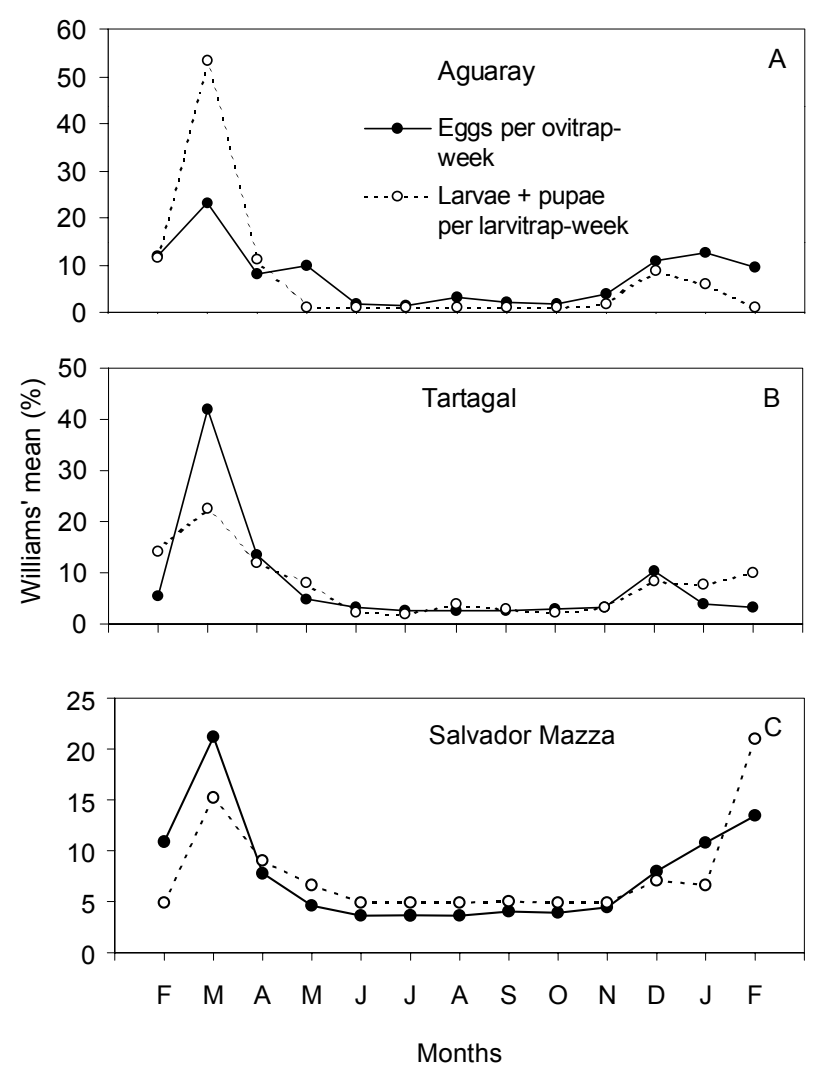

Fig. 1: seasonal and relative abundance of Aedes aegypti immature stages, at Tartagal, Aguaray and Salvador Mazza, subtropical region, Argentina. 

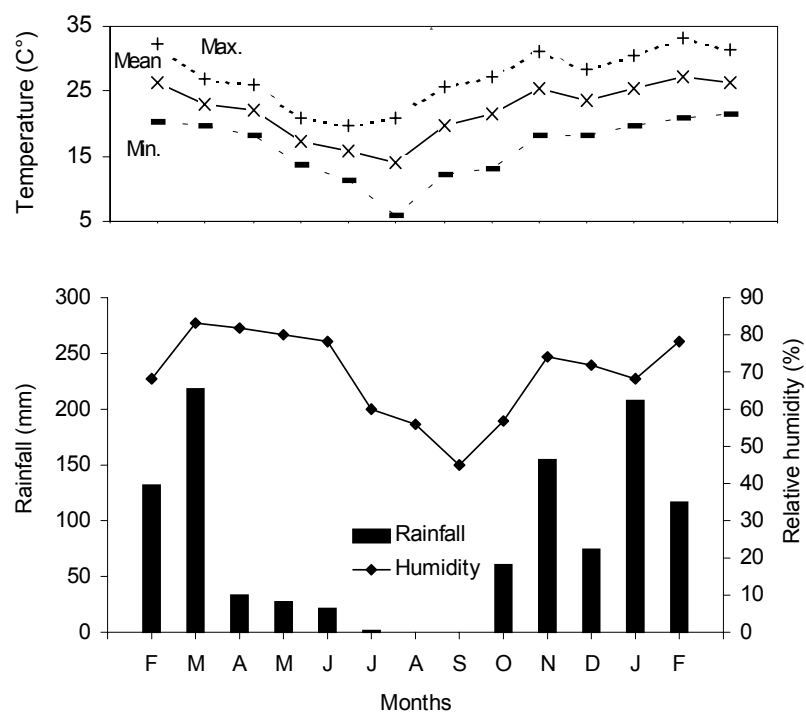

Fig. 2: meteorological conditions at Tartagal from February 1999 to February 2000. A: air temperature; B: total precipitation and relative humidity

mum temperature rose to above $18^{\circ} \mathrm{C}$. Although in October the minimum temperature was $18^{\circ} \mathrm{C}$ and the maximum $31^{\circ} \mathrm{C}$ (Fig. 2A), the mosquito population did not increase (Fig. 1) because rainfall was light (Fig. 2B).

The mean numbers of eggs, larvae and pupae were compared between localities (Fig. 3), but no significant differences were detected $(\mathrm{K}-\mathrm{W} \mathrm{H}$ egg $=4.71, \mathrm{P}=0.09$; $\left.\mathrm{H}_{\text {larva }}=1.72, \mathrm{P}=0.42 ; \mathrm{H}_{\text {pupa }}=1.78, \mathrm{P}=0.41 ; \mathrm{n}=39\right)$.

Oviposition activity - The numbers of wood paddles sampled were 2 576, 642 and 1423 , and egg occurrences were of $44.8 \%, 45.3 \%$, and $27.7 \%$, respectively at Tartagal, Aguaray and Salvador Mazza. There were significant differences between the occurrences of oviposition at the three localities $(\mathrm{K}-\mathrm{W}: \mathrm{H}=12.7, \mathrm{n}=12, \mathrm{P}<0.001)$. A posterior test of multiple comparison, established differences between Tartagal and the other two localities (Table I). On the other hand, no significant differences were observed in the quantity of eggs laid $(\mathrm{H}=3.56, \mathrm{n}=12, \mathrm{P}=0.17)$.

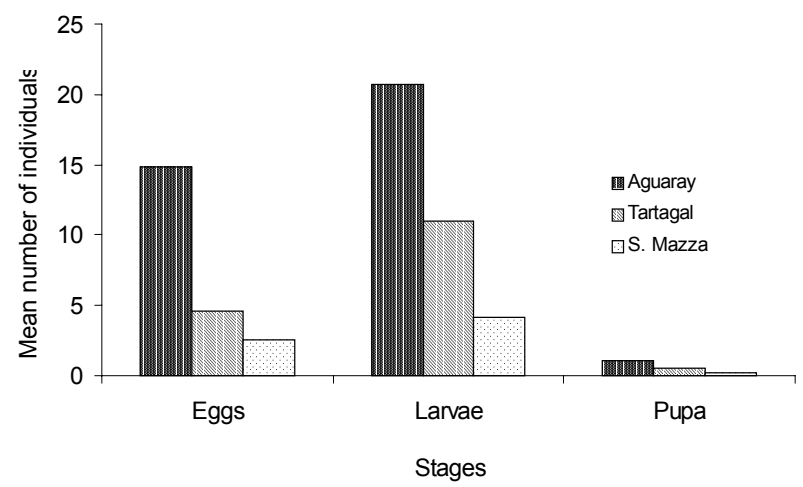

Fig. 3: frequency distribution of immature Aedes aegypti stage at Tartagal $(\mathrm{n}=900 / 18)$, Aguaray $(\mathrm{n}=167 / 4)$ and Salvador Mazza (n $=559 / 11) ; \mathrm{n}: \mathrm{b} / \mathrm{a}$, where " $\mathrm{a}$ " indicates total number of positive larvitraps during whole sampling period, and " $b$ " indicates total number of larvitraps during whole sampling period
TABLE I

Student-Newman-Keuls Test multiple comparison results of the occurrence of oviposition of Aedes aegypti between cities in Salta Province

\begin{tabular}{lccc}
\hline Pair compared & Difference of ranking & $\mathrm{p}$ & $\mathrm{Q}$ \\
\hline Tartagal vs Salvador Mazza & 166.5 & 3 & $4.562^{a}$ \\
Tartagal vs Aguaray & 151.5 & 2 & $6.185^{a}$ \\
Aguaray vs Salvador Mazza & 15 & 2 & 0.612 \\
\hline
\end{tabular}

$a$ : statistical significance with $\mathrm{P}<0.05$

Comparisons between coefficient of variation of oviposition occurrence versus quantity of eggs laid by locality, showed significant differences at Tartagal, being the number of eggs laid more variable than the occurrence (Wilcoxon Pair Test $\mathrm{T}=62, \mathrm{P}<0.01$ ). However, not at either Aguaray $(\mathrm{T}=133, \mathrm{P}=0.63)$, or Salvador Mazza $(\mathrm{T}=147, \mathrm{P}=0.93)$ (Table II).

During the dry season, from July to September (Fig. 2B), the number of eggs was small in all three localities (Fig. 1). Oviposition activity of Ae. aegypti increased when the humidity rose above $60 \%$, after the rainfall in October (Fig. 2B). The maximum oviposition activity was observed during the fall and the summer (Table II) associated with the heaviest rains, which occurred in March and January, respectively (Fig. 2B).

The Cv for both occurrence and quantity of eggs laid were relatively large and heterogeneous between seasons and localities. During the winter, variation in occurrence and quantity of egg laid, were considerably greater than those during the other seasons (Table II).

Comparisons between oviposition occurrences in larvitraps located on the outskirts and in the center of Tartagal were made because it was possible to establish two definite areas within the town as a consequence of its size. This analysis showed homogeneity between the two areas $(\mathrm{K}-\mathrm{W}: \mathrm{H}=0.016, \mathrm{df}=1, \mathrm{n}=13, \mathrm{P}=0.90)$.

\section{DISCUSSION}

The seasonal pattern of Ae. aegypti in subtropical is different from that in temperate Argentina. Campos and Maciá (1996) reported the occurrence of immature $A e$. aegypti in Buenos Aires province (east temperate region) from October to May with a break in the winter months ( $\mathrm{T}^{\circ} \min .: 7^{\circ} \mathrm{C}-15^{\circ} \mathrm{C}$, mean: $10^{\circ} \mathrm{C}-12^{\circ} \mathrm{C}$, and max.: $12^{\circ} \mathrm{C}-$ $16^{\circ} \mathrm{C}$ ); occurring the greatest abundance from December until April with a conspicuous peak during this period. In Córdoba Province (Mediterranean temperate), Avilés et al. (1997) reported Ae. aegypti from December until June, with an extensive break from July to November. On the other hand, Domínguez et al. (2000) related that Ae. aegypti was present in the same province, from October to May but absent from June to September, showing a similar pattern than in Buenos Aires Province. These differences observed by the two authors in Córdoba may be a consequence of annual climatic variations.

Our study in the subtropical region showed a permanent immature population with a low number of individuals and eggs laid in winter with a prominent peak in March. 


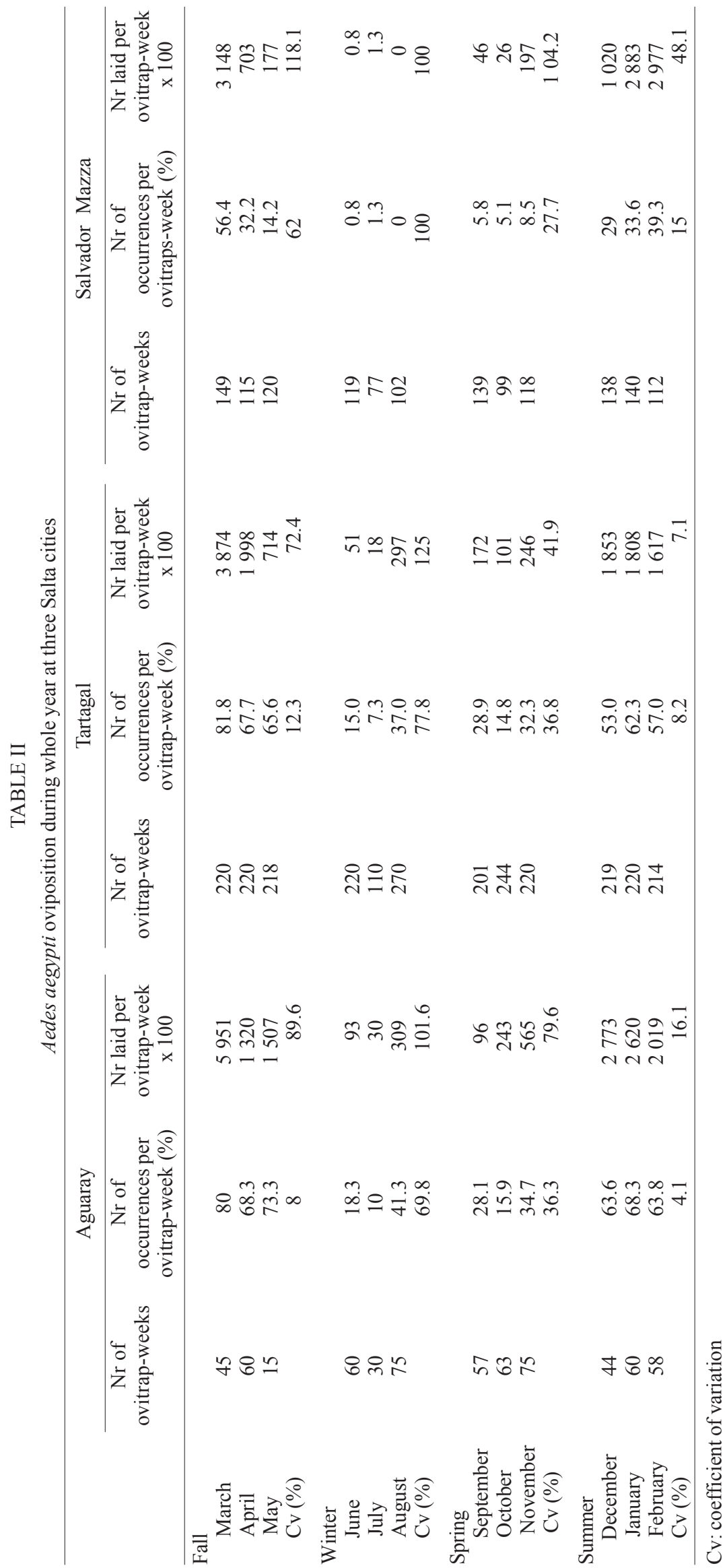


The presence of Ae. aegypti in the winter months (dry season) might be attributed to the high mean temperature (equivalent to the maximum temperature of the temperate region). Conversely, the low abundance might be due to the drought and low relative humidity during this period. Bar-Zeev (1957a, b from Mogi et al. 1988) reported low temperature and humidity in the cool, dry season of Northern Thailand as sub-optimal but which still allowed Aedes to reproduce. Ae aegypti oviposition in Salta showed a similar pattern to that observed by Mogi et al. (1988) in Chiang Mai, Thailand. The egg populations remained low in the dry season, increasing at the beginning and decreasing at the end of the rain season. On the other hand, they reported a higher ratio of ovitraps containing Aedes in the dry than in the wet season, similar to our finding. The high number of occurrences might be a consequence of the relative attraction to the ovitrap due to the scarcity of other suitable artificial containers near the ovitraps.

The seasonal changes in oviposition are a consequence of seasonal changes in weather conditions, and the availability of sites for laying. The increase of $A e$. aegypti oviposition at Aguaray and Tartagal in August (dry season) might be the result of greater female activity, due to an increase in the temperature and relative humidity during this month. The weather remained dry in September, but the relative humidity declined from that of August inducing the gonoactive female to rest, thus leading to a decrease in the Ae. aegypti oviposition.

From a study carried out in Thailand, Southwood et al. (1972) reported that the high survival rate of immature stages at the beginning of the hot season led to a rise in the number of emergent adults. This led, in its area, to an increase in the incidence of dengue transmission. The seasonal pattern of Ae. aegypti in Salta Province showed a peak during March and an increment in the population level in December thus agreeing with Southwood's results. Thus we suspect that the possibility of the transmission of dengue would be greater in Salta Province during this period.

\section{ACKNOWLEDGEMENTS}

To Dr Mario Zaidenberg (Programa Nacional de Paludismo, Ministerio de Salud de la Provincia de Salta), for permission to publish these data, and for his help with the fieldwork; to Dr Walter Almirón (Centro de Entomología, Universidad Nacional de Córdoba) and Lic. Victoria Sy (Instituto de Limnología "Dr. R. Ringuelet, UNLP) for his critical reading of the manuscript, and to the Servicio Meteorológico Nacional, Fuerza Aerea Argentina, for providing us with meteorological data.

\section{REFERENCES}

Almirón WR, Ludueña Almeida FF, Domínguez MC 1999. Preferencia de Aedes aegypti (Diptera: Culicidae) por sitios para oviposición con diferentes niveles de precolonización y exposición al sol. Rev Soc Entomol Argent 58: 159-164.

Avilés G, Cecchini R, Harrington ME, Cichero J, Asis R, Ríos C 1997. Aedes aegypti in Córdoba province, Argentina. $J$ Am Mosq Control Assoc 13: 255-258.

Avilés G, Rangeon G, Vorndam V 1999. Dengue reemergence in Argentina. Emerging Infect Dis 5: 1-4.

Bar-Zeev M 1957a. The effect of temperature on the growth rate and survival of the immature stage of Aedes aegypti (L.). Bull Entomol Res 48: 157-163.

Bar-Zeev M 1957b. The effect of extreme temperatures on different stage of Aedes aegypti (L.). Bull Entomol Res 48: 593-599.

Campos RE, Maciá A 1996. Observaciones biológicas de una población natural de Aedes aegypti (Diptera: Culicidae) en la provincia de Buenos Aires, Argentina. Rev Soc Entomol Argent 55: 67-72.

Carbajo AE, Schweigmann N, Curto SI, Garín A, Bejarán R 2001. Dengue transmission risk maps of Argentina. Trop Med Int Health 6: 3-34.

Christophers SR 1960. Aedes aegypti (L.) the Yellow Fever Mosquito: its Life History, Bionomics and Structure, Cambridge University Press, New York, 739 pp.

Domínguez MC, Ludueña Almeida FF, Almirón W R 2000. Dinámica poblacional de Aedes aegypti (Diptera: Culicidae) en Córdoba capital. Rev Soc Entomol Argent 59: 41-50.

Gaudino N 1916. El dengue. Algunas consideraciones sobre la epidemia de Entre Ríos de 1916. Rev Sanid Mil Argent 15: 617-627.

Haddow AJ 1960. Studies on the biting habitats and medical importance of East African mosquitoes in the genus Aedes. I. Subgenera Aedimorphus, Banksinella and Dummis. Bull Entomol Res 50: 759-779.

Mogi M, Khamboonruang C, Choochote W, Suwanpanitc P 1988. Ovitrap surveys of dengue vector mosquitoes in Chiang Mai, Northern Thailand: seasonal shifts in relative abundance of Aedes albopictus and Ae. aegypti. Med Vet Entomol 2: 319-324.

OPS 1990. Las Condiciones de la Salud en las Américas, Vol. 1, Organización Panamericana de la Salud, Geneve, 503 pp.

Ousset JH, De Ustaran JK, Lombardo B 1967. Erradicación del Aedes aegypti en la República Argentina. Segundas Jornadas Entomoepidemiológicas Argentinas 2: 81-88.

Southwood TRE, Murdie G, Yasuno M, Tonn RJ, Reader PM 1972. Studies on the life budget of Aedes aegypti in Wat Samphaya, Bangkok, Thailand. Bull WHO 46: 211-226.

Vezzani D, Velázquez S M, Soto S, Schweigmann N 2001. Environmental characteristics of the cemeteries of Buenos Aires city (Argentina) and infestation levels of Aedes aegypti (Diptera: Culicidae). Mem Inst Oswaldo Cruz 96: 467-471. 